\title{
Utilising Physical Model for Design Assessment: Proposed Alterations of Batu Dam, Malaysia
}

\author{
Saiful Bahri Hamzah, Mohd Kamarul Huda Samion, and Mohd Fauzi Mohamad
}

\begin{abstract}
Physical model was utilised to make an assessment of Batu Dam spillway, as well as to make informed recommendations of its hydraulic performance and proposed alterations. A scale of 1:25 was chosen for the model for optimum configuration. Simulations with respect to various reservoir levels and discharges to investigate effects of the varied flow conditions were performed. The experiments were run at ten discharge flows under two different conditions, with and without the proposed overflow weir at the inlet. It was found that the transition portion and the spillway chute are adequate for the proposed design discharge but the energy dissipater is insufficient to cater for the high discharge. The proposed overflow weir was not found to have any benefits in terms of controlling high flows equivalent or greater than $64 \mathrm{l} / \mathrm{s}$ as there is no significant difference in the results when compared to test conditions without the overflow weir installed.
\end{abstract}

Index Terms-Dam, hydraulic structure, overflow weir, physical modeling, spillway.

\section{INTRODUCTION}

The uncertainties and lack of complete scientific background to evaluate impacts on various hydraulic structures as well as to confirm design procedures, lead to the use of physical modelling [1]. Physical modelling is an essential tool for testing hydraulic structures before its construction due to its ability to solve complex hydraulic problems. Physical modelling is commonly used during design stages to optimize a structure and to ensure a safe operation of the structure [2]. When used in tandem with numerical modelling, this approach leads to great success for fluid-structure interaction studies and discharge capacity evaluation of dams, for example ([3]-[5]).

Batu Dam is a $39 \mathrm{~m}$ high earth-rock filled dam, and is part of the scheme proposed to mitigate expected water deficit in Selangor and Kuala Lumpur. Apart from raw water pipeline, pump station and upgrading of treatment plant, the scheme will also include the raising of Batu Dam. One of the components of work is the modification at the existing spillway. Existing dam crest is set at $109.5 \mathrm{~m}$ elevation and it was proposed to raise the crest level to $110 \mathrm{~m}$. The existing spillway has a side channel inlet structure with a $23 \mathrm{~m}$ long crest at $104.85 \mathrm{~m}$ elevation. The chute is $145 \mathrm{~m}$ long and ends with a $32.5 \mathrm{~m}$ long energy dissipater (stilling basin) at invert

Manuscript received May 31, 2014; revised December 12, 2014.

Saiful Bahri Hamzah and Mohd Fauzi Mohamad are with the National Hydraulic Research Institute of Malaysia (NAHRIM), Malaysia (e-mail: saiful@nahrim.gov.my, fauzi@nahrim.gov.my)

Mohd Kamarul Huda Samion is with the National Hydraulic Research Institute of Malaysia (NAHRIM), Malaysia (e-mail: kamarul@nahrim.gov.my) level of $60 \mathrm{~m}$. A raw inlet structure with overflow weir will be constructed ahead of the existing spillway. Overflow level is set at elevation of $106.7 \mathrm{~m}$. The new design requirement is to ensure the integrity of the dam and spillway is still intact under Probable Maximum Flood (PMF) of $300 \mathrm{~m}^{3} / \mathrm{s}$, from the original capacity of $200 \mathrm{~m}^{3} / \mathrm{s}$.

The objectives of the study are:

1) to investigate hydraulic behaviour of the spillway and also its ancillary structures under a range of design discharges, and,

2) to investigate the discharge capacity of the prototype and measures the hydraulic parameters.

\section{Methodology}

In general, Froude number modelling is used when friction losses are small and the flow is very turbulent [2]. As the flows studied were mainly controlled by gravity and thus the friction loses could be negligible, the model were adopted with the same ratio between inertia and gravity forces as on the prototype. Hence, it will result in the conservation between model and prototype of the non-dimensional number of Froude [6]. After thorough considerations, the model scale was decided to be set at 1:25 ratio. Thus, in compliance with the Froude Law, $F=[\mathrm{V} / \sqrt{ }(\mathrm{gL})]$, the corresponding model and prototype conditions was summarised in Table I.

TABLE I: MODEL AND PROTOTYPE CONDITIONS FOR HYDRODYNAMIC SIMILARITY

\begin{tabular}{lll}
\hline \hline Quantity & Dimensions & Scale Ratio \\
\hline Length & $L$ & $1: x=1: 25$ \\
Time & $T$ & $1: x^{1 / 2}=1: 5$ \\
Velocity & $L T^{-1}$ & $1: x^{1 / 2}=1: 5$ \\
Discharge & $L^{3} T^{-1}$ & $1: x^{2.5}=1: 3125$ \\
Pressure & $M L^{-1} T^{-2}$ & $1: x=1: 25$ \\
\hline \hline
\end{tabular}

The model was tested under designed Probable Maximum Flood (PMF) scenario of up to $96 \mathrm{l} / \mathrm{s}\left(300 \mathrm{~m}^{3} / \mathrm{s}\right.$ prototype). Water supply was provided by five pumps with a maximum capacity of $16.7 \mathrm{l} / \mathrm{s}$ each and a single pump with a maximum capacity of $50 \mathrm{l} / \mathrm{s}$. Water level measurements were conducted using point gauges at 11 locations, identified as $P_{1}, P_{2}, P_{3}, P_{4}$, $P_{5}, P_{6}, P_{7}, P_{8}, P_{9}, P_{10}$ and $P_{10}$ in Fig. 1 . A $90^{\circ} \mathrm{V}$-notch sharp overflow weir with a calibrated discharge coefficient, $\mathrm{C}_{\mathrm{d}}$, of 0.6 was placed perpendicular to the flow in the downstream end of the outlet tank. The model test were run at ten discharge flows (from $10 \mathrm{l} / \mathrm{s}$ to $96 \mathrm{l} / \mathrm{s}$ ) under two different conditions, with and without the proposed overflow weir at the inlet. Additionally, flow patterns were also observed using photographs and other flow visualisation techniques such as a digital video camera. 


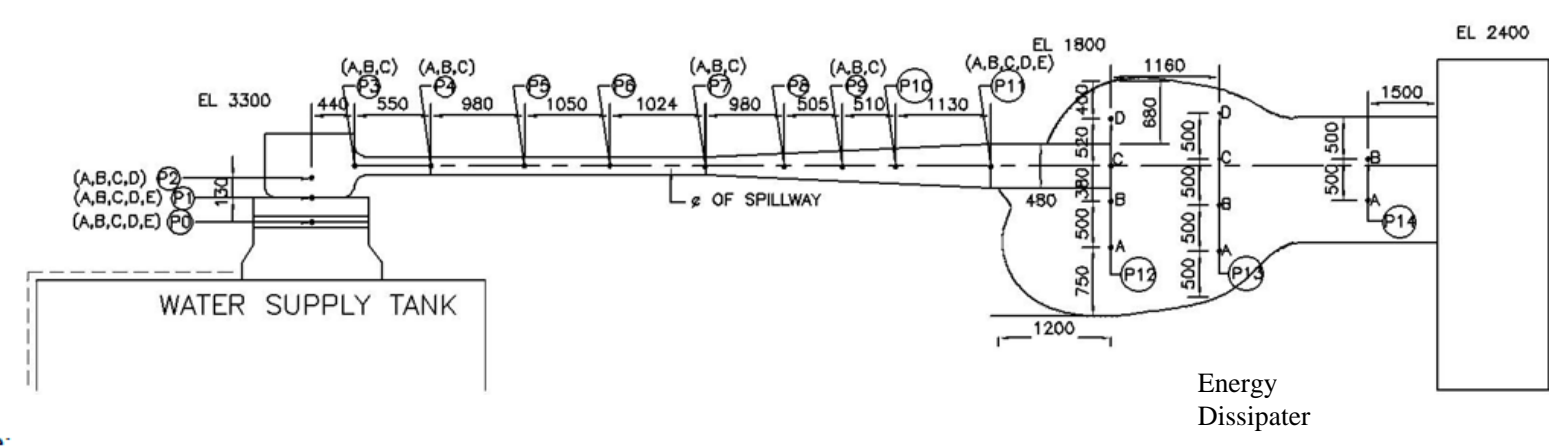

Note:

P1, P2 , .., P14-Measurement locations along the model

A, B, C, D, E- Number of measurement points at each location

Not to scale

If there are no letter, that means there is only one point of measurement

Fig. 1. Plan view showing points numbering along spillway and energy dissipater.

Velocities were measured using the OTT currentmeter at two points along the spillway $\left(P_{5}, P_{9}\right)$ and 3 points in the energy dissipator $\left(P_{12}, P_{13}, P_{14}\right)$. Besides the currentmeter, the average velocity inside the spillway was also calculated by releasing a submerged object at $\mathrm{P} 4$ noting down the time it took to travel to $P_{9}$. Average velocity in the spillway was calculated by dividing the distance traveled by the object with the time note

\section{RESULTS AND DISCUSSION}

Results of the experiments mentioned are analysed at strategic locations of the spillway structure.

\section{A. At intake/Approach Channel and Transition Portion}

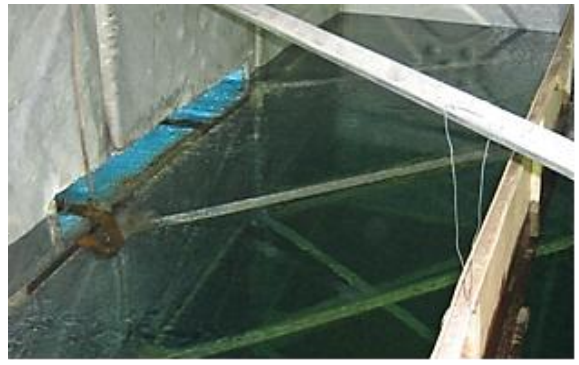

(a)

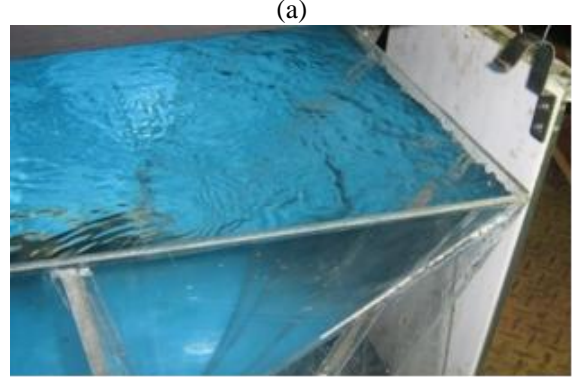

(b)

Fig. 2.1. (a) stabilised inflow shown from side of water supply tank; (b) flow conditions at transition portion

As shown in Fig. 2.1(a), the incoming flow is steady as it has been stabilized before reaching the inlet opening. Each change of discharge rate will require about 5-10 minutes for the water to stabilize. The velocity increases as the incoming discharge increases. From test for the discharge of 96 1/s, it was observed that no freeboard was noticeable. In fact the water frequently overflows the transition portion with occasional swirl eddies occurring at the edge of the transition portion, as shown in Fig. 2.1(b).

\section{B. Along the Spillway Chute and Energy Dissipater}

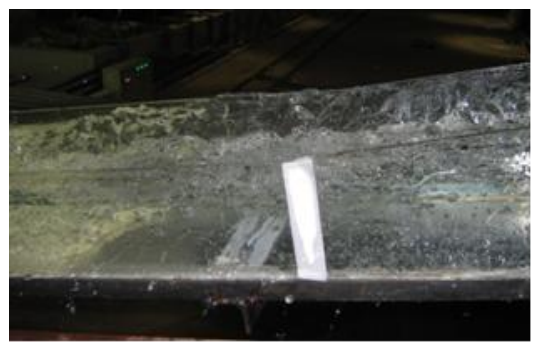

(a)

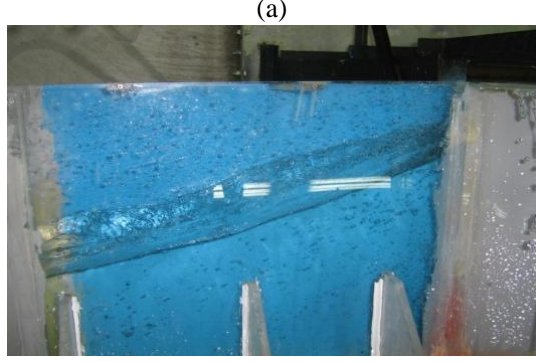

(b)

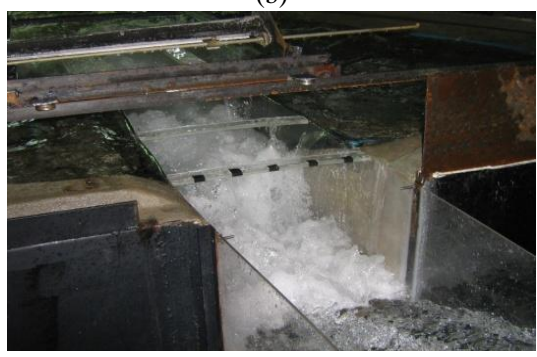

(c)

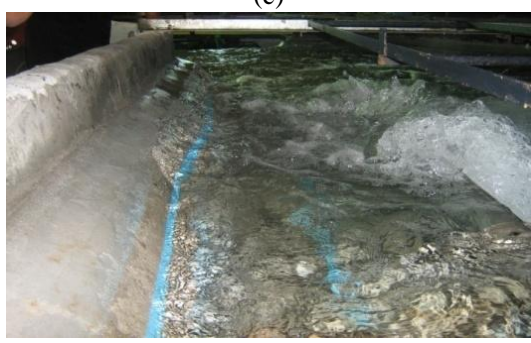

(d)

Fig. 2.2. (a) water overflowing along spillway chute; (b) water surface profile between $P_{3}$ to $P_{5}$; (c) water surface conditions at $P_{11}$; (d) water surface exceeds the blue line in energy dissipater.

For both test conditions with and without overflow weir, point velocity recorded at the beginning of the chute $\left(P_{5}\right)$ is much smaller than the point velocity recorded near the end of 
the chute $\left(P_{9}\right)$. The average velocities for different flow rates in the spillway chute range from $2.58 \mathrm{~m} / \mathrm{s}$ to $4.12 \mathrm{~m} / \mathrm{s}$. Along the spillway chute, for discharge values of $80 \mathrm{l} / \mathrm{s}$ and $85 \mathrm{l} / \mathrm{s}$ for both test conditions, the water in the chute between locations $P_{7}$ and $P_{8}$ starts to spill out as the wall of the chute becomes shorter as it widens. At discharge of $96 \mathrm{l} / \mathrm{s}$, there is a significant loss of water through overflow and spillage between $P_{7}$ and $P_{8}$ as shown in Fig. 2.2(a).

For all values of tested discharge, the water level rose very high at $P_{3}$, then drops gradually from $P_{3}$ to $P_{10}$ along the chute, as shown in Fig. 2.2(b).

Higher discharge values will give higher water levels at all points except for $P_{11}$. The water levels at $P_{11}$ are inversely proportional to the discharge values. Also, the water levels rose dramatically at point $P_{11}$. This is probably due to the levelling out of spillway chute to become flat which creates a hydraulic jump as shown in Fig. 2.2(c).

For tests without overflow weir, it seems that a change of the channel area will cause a spike in pressure readings, as can be seen at $P_{3}$ and $P_{7}$. For both test conditions, the pressure at $P_{4}$ and $P_{6}$ are the lowest for all flow rates. The main difference between Fig. 8 and Fig. 9 is at $P_{3}$ and $P_{9}$ to $P_{10}$. Presence of the overflow weir lowered the pressure at P3 and increased the pressure from $P_{9}$ to $P_{10}$.

\section{In the Energy Dissipater}

In the energy dissipater, the water surface exceeds the blue line markings for discharge values of $32 \mathrm{l} / \mathrm{s}$ and above, as shown in Fig. 2.2(d). The worst hit part of the energy dissipater is between $P_{13}$ and $P_{14}$, near to the side of point A. Overall, the velocity lessened as the water flows from $P_{12}$ to $P_{14}$. Higher discharge values will result in higher velocities at all points in the energy dissipator. Scouring potential is high at point $\mathrm{C}$ of $P_{12}$ and $P_{13}$. Turbulence due to the hydraulic jump as the spillway chute level out into the energy dissipater is contained in the chute for discharge values $64 \mathrm{l} / \mathrm{s}$ and below. At discharge of $80 \mathrm{l} / \mathrm{s}$, the turbulence is halfway out the end of the spillway chute and at a discharge of $96 \mathrm{l} / \mathrm{s}$, the turbulence occurred in the energy dissipater itself, outside the end of the spillway chute.

From Fig. 3, it was also establish that the proposed overflow weir was not found to have any benefit in terms of controlling Probable Maximum Flood (PMF) of $300 \mathrm{~m}^{3} / \mathrm{s}$ as there are no significant differences in the results when compared to test conditions without the overflow weir installed.

\section{CONCLUSION AND RECOMMENDATIONS}

The proposed design required that the spillway must be able to pass the design flood safely downstream when the reservoir is overflowing. Based on this requirement, there are three critical areas of the model identified through observations of the tests results, 1) at the transition portion, 2) at the section between locations $P_{7}$ and $P_{8}$ along the spillway chute, and 3 ) at the energy dissipater (stilling basin).

\section{A. Test Condition 1(without Overflow weir Installed)}

At transition portion, for discharges up to $851 / \mathrm{s}$ (prototype: $\left.265.625 \mathrm{~m}^{3} / \mathrm{s}\right)$, there is still some freeboard left at the transition portion but from test for the discharge of $96 \mathrm{l} / \mathrm{s}$ (prototype: $300 \mathrm{~m}^{3} / \mathrm{s}$ ), it was observed that no freeboard was visible. In fact the water sometimes overflows the transition portion.

At section between $P_{7}$ and $P_{8}$ along spillway chute, for discharges up to $70 \mathrm{l} / \mathrm{s}$ (prototype: $218.75 \mathrm{~m}^{3} / \mathrm{s}$ ), the flow of water was still contained within the chute. Starting from discharge of $80 \mathrm{l} / \mathrm{s}$ (prototype: $250 \mathrm{~m}^{3} / \mathrm{s}$ ), the water in the chute started to overflow occasionally and at a discharge of 96 1/s (prototype: $300 \mathrm{~m}^{3} / \mathrm{s}$ ), there was permanent overflow at the section between $P_{7}$ and $P_{8}$ along the spillway chute.

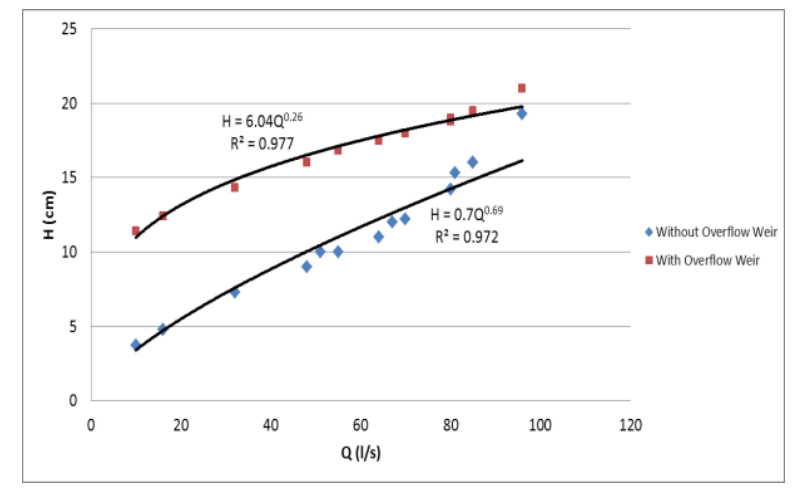

Fig. 3. Discharge as a function of water level (with and without the overflow weir).

At stilling basin, the higher blue line around the stilling basin in the model represents the existing ground level for the prototype. The tests showed that water already reached the blue line for discharge of $32 \mathrm{l} / \mathrm{s}$ (prototype: $100 \mathrm{~m}^{3} / \mathrm{s}$ ) and went above the blue line for discharges of $48 \mathrm{l} / \mathrm{s}$ (prototype: $150 \mathrm{~m}^{3} / \mathrm{s}$ ) and above.

The original design discharge for the Batu Dam spillway prototype is $200 \mathrm{~m}^{3} / \mathrm{s}$ (model: $64 \mathrm{l} / \mathrm{s}$ ). From the tests performed, the transition portion and the section between $P_{7}$ and P8 along the spillway chute is adequate for the original design discharge but the stilling basin (energy dissipator) is inadequate to cater for the high discharge in the original design.

\section{B. Test Condition 2 (with Overflow weir Installed)}

There is not much difference between the results for tests with overflow weir installed and results for tests without overflow weir installed.

At transition portion, the scenario is the same as when no overflow weir is installed; no freeboard was left when discharge is $961 / \mathrm{s}$ (prototype: $300 \mathrm{~m}^{3} / \mathrm{s}$ ). Freeboard was only visible for discharges of $85 \mathrm{l} / \mathrm{s}$ (prototype: $265.625 \mathrm{~m}^{3} / \mathrm{s}$ ) and below.

At section between $P_{7}$ and $P_{8}$ along spillway chute, for discharge of $80 \mathrm{l} / \mathrm{s}$ (prototype: $250 \mathrm{~m}^{3} / \mathrm{s}$ ) and above, water overflowed at the section. At the stilling basin, observation from the tests showed that water just touches the blue line at a discharge of $32 \mathrm{l} / \mathrm{s}$ (prototype : $100 \mathrm{~m}^{3} / \mathrm{s}$ ) and went above the blue line for discharges of $48 \mathrm{l} / \mathrm{s}$ (prototype : $150 \mathrm{~m}^{3} / \mathrm{s}$ ) and above.

As a summary, the proposed overflow weir is not found to have any benefit in terms of controlling high flows (prototype: $\geq 200 \mathrm{~m}^{3} / \mathrm{s}$, model: $\geq 64 \mathrm{l} / \mathrm{s}$ ) as there are no difference in the results when compared to test conditions without the 
overflow weir installed.

The transition portion and spillway chute already adequately caters for the original design discharge of 200 $\mathrm{m}^{3} / \mathrm{s}$ (model: $64 \mathrm{l} / \mathrm{s}$ ). Therefore to cater for a discharge of up to $300 \mathrm{~m}^{3} / \mathrm{s}$, it is recommended that the freeboard at the existing transition portion be increased by at least $3 \mathrm{~m}$ and the wall of the spillway chute between $P_{7}$ and $P_{8}$ be increased by $2 \mathrm{~m}$. For the stilling basin, it is recommended that bunds of $5 \mathrm{~m}$ high be constructed around the perimeter to prevent inundation of the surrounding grounds.

The study had also demonstrated how utilisation of physical model is beneficial to visualize possible shortcomings of proposed dam alteration, optimize structure design to ensure safe operation of the structure; and to aid decision-making process.

\section{REFERENCES}

[1] F. T. Pinto, F. V. Gomes, P. R. Santos, C. G. Soares, N. Fonseca, J. A. Santos, A. P. Moreira, P. Costa, and E. B. Dias, "Analysis of the behaviour of moored tankers," in Proc. the 27th International Conference on Offshore Mechanics and Arctic Engineering OMAE2008, Estoril, Portugal, July 15-20, 2008, vol. 10.

[2] H. Chanson, The Hydraulics of Open Channel Flow, Euston Road, London NW1 3BH, UK, 1999.

[3] P. Archambeau, S. Erpicum, T. Mouzelard, and M. Pirotton, "Experimental - numerical interaction: an example of a large dam in Laos," Water Resources Management, Boston, pp. 365-374, 2013.

[4] M. Pirotton, P. Archambeau, S. Erpicum, and T. Mouzelard, "Water management of large dams," in Proc. International Symposium on Environmental Hydraulics, 2001.

[5] M. Pirotton, A. Lejeune, P. Archambeau, S. Erpicum, and B. Dewals, "Numerical-experimental interaction in hydrodynamics: An integrated approach for the optimal management of hydraulic structures and hydrographic basins," in Proc. the 9th International Conference on Enhancement and Promotion of Computational Methods in Engineering and Science, University of Macau, Macao, 2003.

[6] S. Erpicum, B. Dewals, P. Archambeau, S. Detrembleur, C. Fraikin, and M. Pirotton, "Scale modelling and similarity laws for the study of an under pressure settling structure," in Proc. the 9th International Symposium on River Sedimentation, 2008, vol. 2.

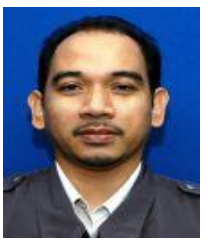

Saiful Bahri Hamzah was born in 1973 and $\mathrm{He}$ received his bachelor degree (Hons) in civil engineering from University of Malaya in 1998, and He received his master of science in environment at University Putra Malaysia in 2009.

$\mathrm{He}$ has been serving in National Hydraulic Research Institute of Malaysia (NAHRIM) since 1999. At NAHRIM, he holds the position of senior research officer in Hydraulic and Instrumentation Laboratory.

$\mathrm{He}$ is currently the head researcher in charge of hydraulic and hydrological model testing project particularly in flood mitigation study and hydraulic structure. He had carried out numerous physical modelling for many rivers, dam and coastal in Malaysia.

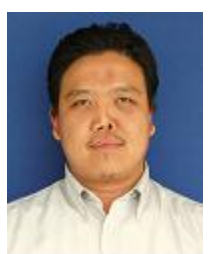

Mohd Kamarul Huda Samion was born in 1980. He received his bachelor degree (Hons) in civil engineering at UTM, Malaysia (2003), and he received his master of science in hydraulic and hydrology at University Technology Malaysia (2006).

$\mathrm{He}$ has been serving at National Hydraulic Research Institute of Malaysia (NAHRIM) since 2007. At NAHRIM, he holds the position of research officer on Laboratory of Hydraulic and Instrumentation.

$\mathrm{He}$ is currently a researcher in charge of hydraulic and hydrological model testing project particularly in flood mitigation study and hydraulic structure. He has carried out numerous physical modelling for many rivers, dam and coastal in Malaysia.

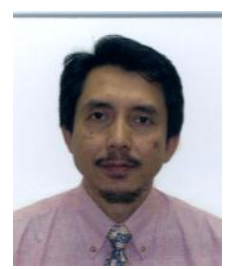

Mohd Fauzi Mohamad was born in 1959 and He received his diploma in civil engineering at MARA Institute of Technology, Malaysia in 1981. He received his bachelor of science (Hons) in civil engineering at University of Strathclyde, United Kingdom (1983) and a master degree in hydrology and water resources at Universiti Teknologi Malaysia in 2009.

He served at Jabatan Kerja Raya (JKR) from 1983 to 2001, before serving at National Hydraulic Research Institute of Malaysia (NAHRIM) since 2001. At JKR, he held the position of senior executive engineer before serving at NAHRIM as a senior researcher on Coastal Engineering Division from 2001 to 2003 and as the director of Hydraulic and Instrumentation Laboratory from 2003 until now.

Mohd Fauzi has vast experience in project management and structural design with major in coastal structures during his tenure in JKR and has produces several research technical papers. He is a professional engineer, a member of Board of Engineer Malaysia (BEM) and a corporate member at the Institution of Engineer Malaysia (IEM). 